\title{
Resolution of 2nd, 3rd or 4th interdigital space incomplete, simple syndactyly using a random vascularity flap
}

\author{
Heriberto Garza de la Llave ${ }^{1}$, Yusef Jiménez Muratt ${ }^{1}$, Alejandro Ángel Corona Figueroa ${ }^{2}$ \\ ${ }^{1}$ Hand Surgery Clinic, Plastic and Reconstructive Surgery Department, Hospital General Dr. Manuel Gea González, Mexico City 14080, Mexico. \\ ${ }^{2}$ Facultad Mexicana de Medicina, Universidad La Salle, Mexico City 14000, Mexico.
}

Correspondence to: Dr. Heriberto Garza de la Llave, Hand Surgery Clinic, Plastic and Reconstructive Surgery Department, Hospital General Dr. Manuel Gea González, Av. Calzada de Tlalpan 4800 Col. Sección XVI, Deleg. Tlalpan, Mexico City 14080, Mexico. E-mail: dr.garzadelallave@gmail.com

How to cite this article: Garza de la Llave H, Jiménez Murat Y, Corona Figueroa AÁ. Resolution of 2nd, 3rd or 4th interdigital space incomplete, simple syndactyly using a random vascularity flap. Plast Aesthet Res 2017;4:70-5.

\section{Article history: \\ Received: $20-12-2016$ \\ Accepted: 28-03-2017 \\ Published: 27-04-2017}

Key words:

Syndactyly,

interdigital space,

flap,

skin graft

\begin{abstract}
Syndactyly consists of a variable fusion of soft tissue or of bone in adjacent fingers. This has important aesthetic and functional impacts on the development of the child due to the abnormal appearance of the hand. When the 1st web space is affected, it compromises grasp and development of the clamp function. Affliction of the $2 \mathrm{nd}$, 3rd or 4 th webspaces hinder the independent movement of the fingers adjacent to it. Current syndactyly release techniques have inherent disadvantages such as the use of skin from both the interdigital halves of the syndactylized fingers, the need to skin graft the donor site, postoperative flexion contracture, and need of 2 or more surgical procedures to obtain the desired result. The authors present 7 cases with incomplete simple 2nd, 3rd or 4th webspace syndactylies of multiple etiologies. All cases were treated at the unit of the corresponding author. The flap used in the treatment for all 7 cases did not require skin grafting of the flap donor site and used only skin from one of the fingers, while achieving a webspace dimension similar to normality, with a short recovery period. Furthermore, there were no postoperative finger contractures, diminishing the risk of future relapse.
\end{abstract}

\section{INTRODUCTION}

Syndactyly is one of the most common congenital anomalies, with an incidence of 1 in 2,000-2,500 live births. ${ }^{[1-3]}$ The etiology of syndactyly can be broadly divided into either congenital or acquired, with the latter predominantly secondary to burns. Its classification is based on the degree of soft tissue and bony involvement. Simple syndactyly affects only skin and soft tissue between the affected fingers, whereas complex syndactyly has additional bony involvement. The distinction between a complete and incomplete syndactyly is determined by the extent of fusion in the proximal-distal axis. A complete syndactyly occurs when fusion involves the entire webspace from commissure up to and including the nail fold. The incomplete syndactyly in contrast, encompasses all fusions from the commissure that

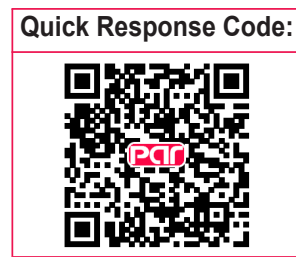


fall short of the nail fold.

The goal of treatment is to create a functional hand with minimal long-term morbidity. In order to achieve this, an aesthetically pleasing and functional interdigital space must be created preferably with as few procedures as possible. ${ }^{[4]}$ The current techniques available are based at the opening of the webspace with the purpose of obtaining a normal webspace while supplying adequate skin coverage for it. ${ }^{[1,5-7]}$ These surgical techniques can be classified into two types: those utilizing a local flaps alone and those that use skin grafting in addition to it. The latter technique is used especially in difficult cases of complete syndactyly to treat the fusion distal to distal interphalangeal joint. However in mild cases, such as incomplete syndactyly proximal to the proximal interphalangeal joint, various techniques for correcting the web only with local flaps from surrounding tissues have been reported. ${ }^{[8]}$ Some of the techniques used to recreate the webspaces include split and full-thickness skin grafts ${ }^{[9]}$ Examples of local flaps used are such as the dorsal rectangular, palmar rectangular, interposed "V", dorsal metacarpal. ${ }^{[10]}$ The proximally-based dorsal rectangular flap is most commonly used ${ }^{[11]}$ The main complications of corrective surgery are infection, delayed wound healing, graft loss, flap loss, syndactyly relapse and contracture of adjacent fingers. ${ }^{[12]}$

\section{CASE REPORT}

\section{Surgical technique \\ Marking}

The depth of a normal adjacent webspace is measured and compared to the affected interdigital space. This is done to obtain the intended target webspace depth for the procedure [Figure 1]. The target depth is marked in the affected web using methylene blue dye. The marking can be made either on the dorsal or palmar side of web, depending on the quality of the skin or presence of scars. After due consideration for the required flap size, and the quality and quantity of the skin available in both adjacent fingers, one of the fingers is selected to design the flap on. The presence of adequate tissue laxity is verified to ensure a primary closure of the donor site. A proximally-based flap with a length matching the target webspace depth is then outlined. A length to base-width ratio of 3:1 for the flap is respected. The most-distal portion of the flap donor site must not surpass the proximal interphalangeal joint, so as to reduce the risk of subsequent contracture [Figure 2].

\section{Anesthesia}

The procedure can be performed under either general or local anesthesia. Pre-operative exsanguination of the hand is used in all cases and can be achieved with an Esmarch bandage or pneumatic device (Kidde).

\section{Creation of the new webspace opening}

Under $\times 3.5$ surgical loupe magnification, the syndactylized soft tissue is incised with a 15 blade along the previous markings to achieve the desired webspace depth [Figure 3]. Blunt dissection of the interdigital space is performed with special consideration taken to release the natatory ligament and to preserve the digital neurovascular bundles [Figure 4].

\section{Flap dissection}

The skin and subcutaneous tissue of the flap is dissected along the pre-marked limits. Distal to proximal dissection is performed with thin curved scissors, achieving adequate flap thickness without damaging the main vascular pedicle of the finger. Only the skin and the subcutaneous tissue should be raised with the flap and must not include the main vascular pedicle of the finger. Thus, the flap is of a vascular random pattern variety and must not exceed the length to base width ratio of $3: 1$ to ensure its vascular viability [Figure 5].

\section{Flap rotation}

The dissected flap must be able to freely rotate to
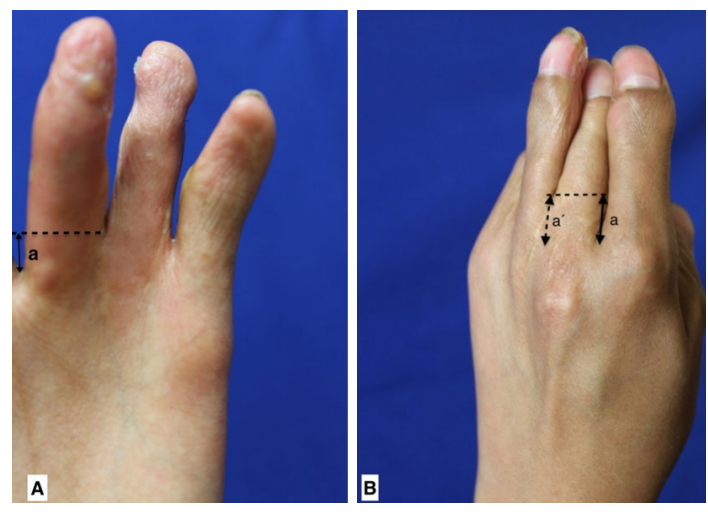

Figure 1: (A) Palmar view; (B) dorsal view. a: normal interdigital space depth; a': desired interdigital space depth

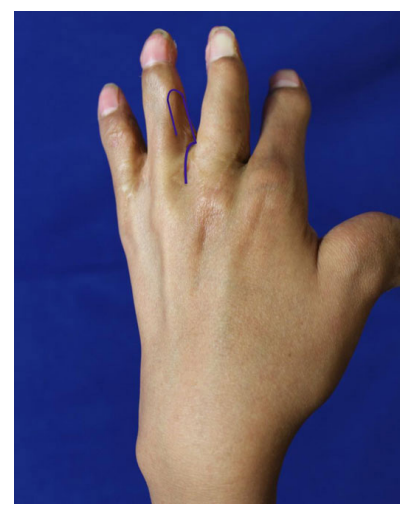

Figure 2: Flap design and marking 


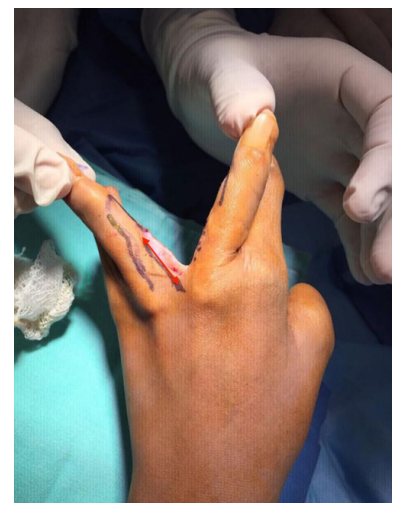

Figure 3: Surgical incision according to the desired web space depth

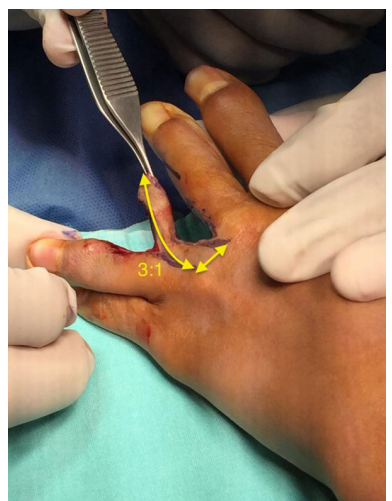

Figure 5: 3:1 (length:base) relationship to ensure vascularity

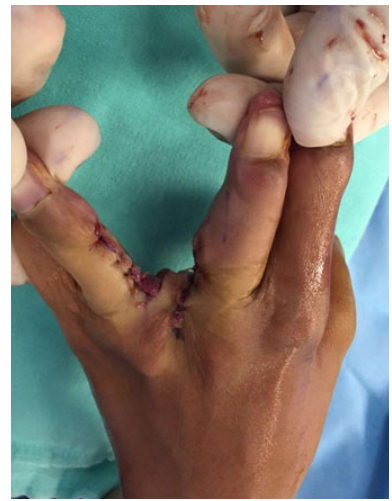

Figure 7: Flap fixation and donor site primary closure

achieve full coverage of the newly created webspace. Then the flap can be tailored away to remove redundant skin [Figure 6].

\section{Flap fixation and closure}

Single sutures of 5-0 Vicryl are placed to secure the flap in the desired position. The donor site is closed primarily with simple interrupted 5-0 absorbable sutures [Figure 7]. Care must be taken to avoid any kind of tension on the donor finger that may modify the shape of the finger, cause deformity, limit finger movement or cause ischemia. The hand is splinted in a neutral position for the first post-operative week.

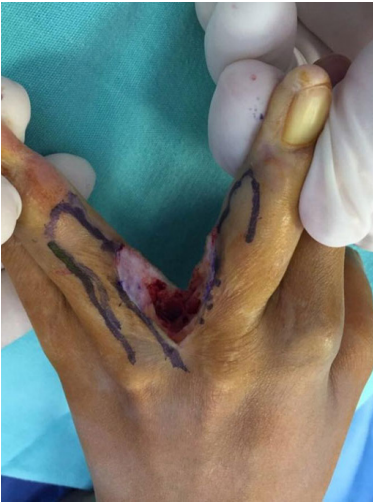

Figure 4: Interdigital space dissection

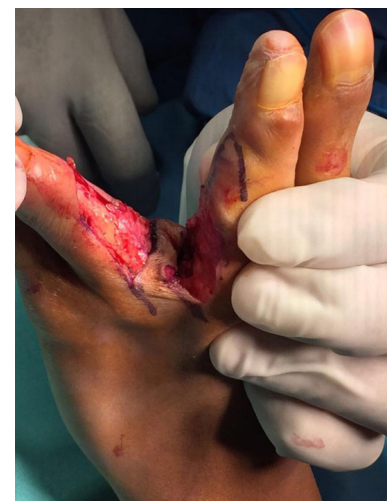

Figure 6: Flap rotation

\section{Postoperative care}

Post-operative analgesia and prophylactic antibiotics are recommended. Patients are discharged from hospital the next day. Moisture at the surgical site can modify the results of the procedure and may cause wound dehiscence or infection and must be carefully managed. Suture removal is unnecessary as absorbable sutures are used. Scar moisturization can commence at the 2-week point. Patients are reviewed at the hand surgery clinic weekly during the first month, monthly for the next 2 months and every 2 months subsequently until final clinic discharge.

\section{Outcome}

We present 7 cases with incomplete simple syndactyly of the 2nd, 3rd or 4th webspace of multiple etiologies, presenting to the hand surgery service of the corresponding author and operating between February 2015 and May 2016. Cases include both unilateral and bilateral presentations of syndactyly [Table 1].

A proximally-based vascular random pattern flap was used to provide skin coverage to the webspace in all cases.

The demographics comprised 4 males and 3 females of an average age of 10.14 years (range $1-18$ years). 
Table 1: Details of patients

\begin{tabular}{|c|c|c|c|c|c|c|c|c|c|c|c|}
\hline $\begin{array}{l}\text { Case } \\
\text { No. }\end{array}$ & $\begin{array}{c}\text { Age } \\
\text { (year) }\end{array}$ & Gender & Disease & $\begin{array}{l}\text { Affected } \\
\text { area }\end{array}$ & $\begin{array}{c}\text { Affected web } \\
\text { space }\end{array}$ & $\begin{array}{l}\text { Treated web } \\
\text { space }\end{array}$ & Complication & $\begin{array}{c}\text { Operating } \\
\text { time } \\
\text { (h:min) }\end{array}$ & $\begin{array}{l}\text { Hospital } \\
\text { stay (day) }\end{array}$ & Result & $\begin{array}{c}\text { Follow } \\
\text { up } \\
\text { (month) }\end{array}$ \\
\hline 1 & 1 & $M$ & SIS & Right hand & 2nd & 2nd & None & $00: 32$ & 1 & Good & 2 \\
\hline 2 & 18 & M & BS & Both hands & $\begin{array}{c}\text { 2nd, 3rd both } \\
\text { hands }\end{array}$ & $\begin{array}{c}\text { 2nd, 3rd both } \\
\text { hands }\end{array}$ & None & 01:25 & 1 & Good & 4 \\
\hline 3 & 16 & $\mathrm{~F}$ & SIS & Left hand & $3 r d$ & 3rd & None & $00: 42$ & 1 & Good & 1 \\
\hline 4 & 2 & $\mathrm{~F}$ & SIS & Left hand & 4th & 4th & $\begin{array}{c}\text { Wound } \\
\text { dehiscence }\end{array}$ & $00: 35$ & 1 & Good & 2 \\
\hline 5 & 14 & M & ABS & Right hand & 2nd & 2nd & None & $00: 40$ & 1 & Good & 2 \\
\hline 6 & 7 & $\mathrm{~F}$ & BS & Both hands & $\begin{array}{c}\text { 2nd, 4th right, } \\
\text { 4th left } \\
\text { 2nd, 4th right. }\end{array}$ & $\begin{array}{c}\text { 2nd, 4th right, } \\
\text { 4th left }\end{array}$ & None & 01:35 & 1 & Good & 2 \\
\hline 7 & 13 & M & AS & Both hands & $\begin{array}{c}\text { 2nd, 3rd, 4th } \\
\text { left }\end{array}$ & 3rd left & None & $00: 47$ & 1 & Good & 1 \\
\hline
\end{tabular}

M: male; F: female; SIS: simple incomplete syndactyly; ABS: amniotic band syndrome; BS: burn sequels; AS: apert syndrome

Two patients had Apert syndrome and amniotic bands. Two further patients had syndactylies from burns and the remaining 3 as isolated non-syndromic congenital syndactylies. Two patients each had either the left and right hand involved. The remaining 3 had bilateral involvement. Three patients were recurrent syndactylies from previous syndactyly surgeries.

Complications included a case of partial dehiscence of the surgical wound on the third post-operative day. This was subsequently healed by secondary intention without affecting the functional outcome of the procedure.

All flaps were viable and continue to be monitored at the clinic to assess hand function.

\section{DISCUSSION}

The vascular random pattern flap has some inherent advantages such as a short surgical time. Neither dissection of the vascular pedicle with a microscope nor skin grafts were necessary. It is also a technically simple operation to perform and does not have a steep learning curve. In addition, this can be a day surgery procedure or at most an overnight stay, making it convenient for patients. There is also reduced morbidity by using only 1 finger as a donor site for the flap and having the donor site closed primarily. The latter eliminates the lengthy healing process for a skin graft and shortens the healing period to 5-10 days, the time taken for a primarily closed wound to heal. Aesthetic modification of the donor finger can already be seen after primary closure, and this continues to improve with time.

Techniques using skin grafts may result in higher rates of early postoperative complications (infection, flap necrosis, graft failure), web creep, contracture, hypertrophic scarring and revisional surgery when compared with advancement flaps. ${ }^{[13]}$ Previous studies have shown that skin grafts increase the risk of web creep by exerting tension across the web space, particularly when the graft abuts either the dorsal commissure flap or palmar scar junction. ${ }^{[12]}$

Of the surgical techniques reviewed, those described by Matsumine et al. ${ }^{[11]}$ in 2011. Hsu et al. ${ }^{[14]}$ in 2010 and Yamashita et al ${ }^{[8]}$ in 2016 do not require the use of a skin graft for the flap donor site. However, these techniques require using tissue from both adjacent fingers to recreate the desired space.

Our series has a zero flap failure rate. We propose that the use of a vascular random pattern flap instead of an axial pattern flap reduces the risk of pedicle-related complications such as bending, injury or thrombosis of the same. There has been no flexion contractures at the four-month follow-up and can be explained by the fact that the skin used to cover the created interdigital space grows in the same direction and speed at which the finger grows. The flap length that does not surpass the level of the proximal inter-phalangeal joint may also contribute to the favorable lack of flexion contracture seen in our case series. This flap is versatile and can be altered to utilize either the dorsal or palmar skin to reopen the affected space. This is useful when there may be unfavorable features such as scars or other characteristics that diminish the quality of the skin on either surface. As skin from only one finger is used, there is a choice to either use the radial side of one finger or ulnar side of the other, depending on the skin quality on the finger.

This flap can also be used to tackle cases of relapse where other options may already have been exhausted previously. This technique is also a good option for the management of burn syndactyly as the scar tissue can 


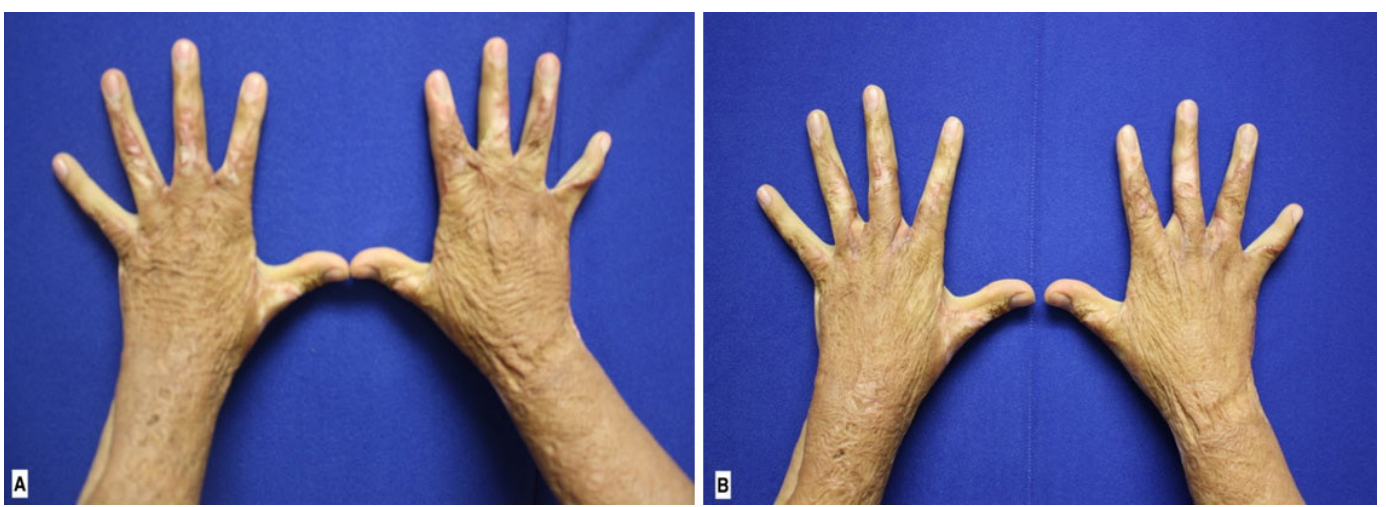

Figure 8: Dorsal view. Preoperative and 4 months postoperative comparison of a 18-year-old patient with burn sequels in both hands. The 2nd and 3rd interdigital spaces were opened using the proposed technique. (A) Preoperative view; (B) 4 months postoperative view
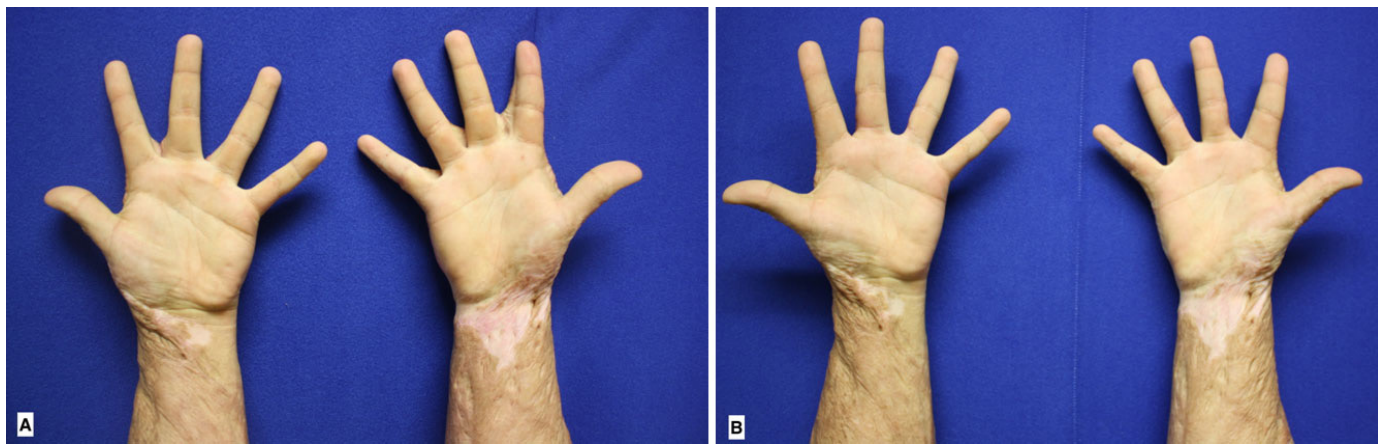

Figure 9: Palmar view. Preoperative and 4 months postoperative comparison of a 18-year-old patient with burn sequels in both hands. The 2nd and 3rd interdigital spaces were opened using the proposed technique. (A) Preoperative view; (B) 4 months postoperative view

be included in the rotation flap forwebspace coverage [Figures 8 and 9].

The possible disadvantages of this flap include the risk of vascular insufficiency of the flap if an insufficiently broad base (at least a 3:1 length-base relationship) is not adhered to. There is also a risk of vascular compromise if a wide donor area is taken and primary closure is performed under tension. Flexion contracture of the proximal inter-phalangeal joint of the donor finger can occur it the length of the flap surpasses the level of this joint and if sufficient dissection is not performed adequately. Another disadvantage of the proposed flap is that both sides of a finger cannot be used simultaneously as flap donors. This is due to the risk of vascular compromise for the donor finger as well as the functional (flexion contraction) and aesthetic (deformity of the finger) complications that may arise.

The proposed flap only improves soft tissue and as such its use is limited to simple syndactyly cases. As the flap cannot surpass the proximal interphalangeal joint, its use is limited to cases of incomplete syndactyly.

Because of the large quantity of soft tissue needed to resurface the first webspace, we do not consider this flap a good option for these cases. The amount of soft tissue that can be taken from the donor finger while allowing primary donor site closure is exceeded in most of these cases.

Possible complications of this flap include wound dehiscence, infection, flap necrosis, flexion contracture of the donor finger, and syndactyly relapse. In our experience, this flap did not present any of the aforementioned complications with the exception of one case of surgical wound dehiscence that was resolved. No other complications were seen in our case series.

\section{Authors' contributions}

Manuscript's preparation: H. Garza de la Llave Manuscript's review: Y. Jiménez Murat Concept design: H. Garza de la Llave Literature search: A.Á. Corona Figueroa

\section{Financial support and sponsorship}

None.

\section{Conflicts of interest}

There are no conflicts of interest. 


\section{Patient consent}

All operations and photographs were performed after the patients' written consent.

\section{Ethics approval}

\section{Obtained.}

\section{REFERENCES}

1. Eaton CJ, Lister GD. Syndactyly. Hand Clin 1990;6:555-75.

2. Flatt AE. The Care of Congenital Hand Anomalies. 2nd ed. St. Louis: Quality Medical; 1994. p. 228-52.

3. Toledo LC, Ger E. Evaluation of the operative treatment of syndactyly. J Hand Surg 1979;4:556-64.

4. Hsu VM, Smartt JM Jr, Chang B. The modified V-Y dorsal metacarpal flap for repair of syndactyly without skin graft. Plast Reconstr Surg 2010;125:225-32.

5. Yao JM, Shong JL, Sun H, Xu JH, Ye P. Repair of incomplete simple syndactyly by a web flap on a subcutaneous tissue pedicle. Plast Reconstr Surg 1997;99:2079-81.

6. Cronin TD. Syndactylism: results of zig-zag incision to prevent postoperative contracture. Plast Reconstr Surg 1956;18:460-8.
7. Van der Biezen JJ, Bloem JJ. Dividing the fingers in congenital syndactyly release: a review of more than 200 years of surgical treatment. Ann Plast Surg 1994;33:225-30.

8. Yamashita K, Yotsuyanagi T, Yamauchi M, Sugai A, Gonda A, Kato S, Kita A. Subcutaneous pedicle V-Y flap for release of incomplete congenital syndactyly. J Plast Reconstr Aesthet Surg 2016;69:e186-91.

9. Deunk J, Nicolai JP, Hamburg SM. Long-term results of syndactyly correction: full-thickness versus split-thickness skin grafts. $J$ Hand Surg Br 2003;28:125-30.

10. Sherif MM. V-Y dorsal metacarpal flap: a new technique for the correction of syndactyly without skin graft. Plast Reconstr Surg 1998;101:1861-6

11. Matsumine H, Yoshinaga Y, Fujigawa O, Sasaki R, Takeuchi M, Sakurai H. Improved "bell-bottom" flap surgical technique for syndactyly without skin graft. Plast Reconst Surg 2011;128:504-9e.

12. Brown PM. Syndactyly -- a review and long term results. Hand 1977;9:16-27.

13. Sullivan MA, Adkinson JM. A systematic review and comparison of outcomes following simple syndactyly reconstruction with skin grafts or a dorsal metacarpal advancement flap. J Hand Surg Am 2017;42:34-40.

14. Hsu VM, Smartt JM, Chang B. The modified V-Y dorsal metacarpal flap for repair of syndactyly without skin graft. Plast Reconstr Surg 2010;125:225-32 